\title{
BREVE ESTUDO GENEALÓGICO DE CECÍLIO DO REGO ALMEIDA ${ }^{1}$
}

\author{
Fernando Marcelino Pereira ${ }^{2}$
}

- Enviado em 11/04/2016

- Aprovado em 25/05/2016

\section{RESUMO}

O objetivo deste artigo é descrever e analisar o perfil social e político dos integrantes da família de Cecílio do Rego Almeida, fundador e proprietário da CR Almeida, uma das maiores empresas da história do Paraná.

Palavras-chave: Genealogia. Cecílio do Rego Almeida. Família. Trajetória.

\section{INTRODUÇÃO}

Este artigo visa explorar as linhas genealógicas da família de Cecílio do Rego Almeida (1930-2008), um dos empresários mais controvertidos do Paraná, engenheiro civil e presidente do grupo bilionário CR Almeida, formado por dezenas de empresas que atuam em diversas áreas. Cecílio já apareceu na lista da revista Forbes entre os cem homens mais ricos do mundo. Durante sua vida criou uma grande rede de cumplicidades e mútuos benefícios entre diferentes poderes e instituições do Paraná e do Brasil.

\footnotetext{
1 Artigo apresentado à disciplina HSO756 - Tópicos especiais em Sociologia Política II, ministrada pelo Prof. Dr. Ricardo Costa de Oliveira no segundo semestre de 2015.

${ }^{2}$ Graduado em Relações Internacionais pela UNICURITIBA, Mestre em Ciência Política e Doutorando em Sociologia pela UFPR. Membro do Núcleo de Estudos Paranaenses (NEP). Endereço eletrônico: fernandomarcelinopereira@gmail.com
} 


\section{SOBRE A FAMÍLIA REGO ALMEIDA}

Cecílio nasceu numa família pobre saída de Pernambuco para o Pará no início do surto da borracha. Seu pai Raymundo Ramos da Costa Almeida (1891 - 1987) era carteiro.

Casou com Cecília do Rego Almeida, dona de casa. Vieram para o Paraná a convite de João Malta de Albuquerque Maranhão. Como Cecílio disse numa entrevista "Como [João] era muito amigo do meu pai, escreveu uma carta para que saísse do Norte porque em cem anos a nossa família não teria a oportunidade que o Sul dava. Então, viemos e ficamos hospedados na casa dele, em Curitiba. E hoje essa família é como se fosse minha família, e minha família é como se fosse a família Albuquerque Maranhão"3.

João Malta de Albuquerque Maranhão descendente de Jerônimo de Albuquerque, nasceu em Águas Belas (PE), era filho de Manoel Ramos de Albuquerque Maranhão e Anna Ramos de Albuquerque Maranhão. Matrimoniou-se com Amélia de Oliveira Maranhão, filha de Miguel Rufino de Oliveira e de Ana Rufino de Oliveira, ele proprietário de Seringal em Manaus (AM). João Malta chegou a Capitão do Exército; dando baixa no exército, passou a laborar nos correios e telégrafos e, também, como presbítero. Teve ao todo 12 (doze) filhos, dentre eles Jerônimo de Albuquerque Maranhão casado com Leonor Neves Pires e Guilherme de Albuquerque Maranhão casado com Jandira Sales ${ }^{4}$.

Jerônimo de Albuquerque Maranhão nasceu em Manaus (AM), em 04 de agosto de 1925. Ingressou no Ministério Público em janeiro de 1952, como promotor público da Comarca de São João do Triunfo. Em 1954 foi removido para Palmeira, após para Mallet, Morretes, Tomazina e Bocaiúva do Sul. Em 1957, foi promovido, por merecimento, para o cargo de promotor público de $2^{a}$ entrância da Comarca de Araucária. Em 1960, foi elevado à $4^{\mathrm{a}}$ entrância. Em 1963, foi eleito vereador pelo P.T.B. da cidade de Araucária, exercendo o cargo cumulativamente com a promotoria do Júri, em Curitiba. Na Capital, desde 1964, ocupou várias promotorias e curadorias. Foi

\footnotetext{
${ }^{3}$ Revista Caros Amigos - Ano 09 - Ed. 102, p.26-33.

4 Sobre a família Albuquerque Maranhão no Paraná ver "Elites e Parentesco no Sistema Judicial Paranaense", Dissertação de mestrado de Henry Levi Kaminski, UFPR, Curitiba, 2013.
} 
promovido, em 1966, ao cargo de $3^{\circ}$ promotor de entrância especial. Nos anos de 1966 a 1968, foi por diversas vezes designado para funcionar no Tribunal do Júri. Promovido, em abril de 1977, ao cargo de Procurador da Justiça, integrou o Conselho Superior da Instituição por vários períodos. Em novembro do mesmo ano, foi nomeado para compor, como membro, o Conselho de Curadores da Fundação Instituto de Terras e Cartografia - ITC, por quatro anos; em dezembro do mesmo ano, foi nomeado para o cargo de Diretor da Polícia Civil, da Secretaria de Segurança Pública, no Governo de Jayme Canet Júnior. Nomeado, em 1979, Corregedor-Geral do Ministério Público. Em dezembro de 1983, foi nomeado Diretor Geral da Casa Civil no Governo de José Richa. De 1985 a 1989 exerceu a procuradoria-geral de Justiça, cargo para o qual foi nomeado a 13 de maio. Faleceu em 14 de maio de 1995.

Guilherme de Albuquerque Maranhão nasceu a 31 de dezembro de 1915. Concluiu seus estudos secundários em 1933, bacharelando-se em Direito em 1938 pela Universidade do Paraná. Membro do Ministério Público por mais de 30 anos ingressou na carreira em 1940 quando foi nomeado adjunto de promotor do distrito de Reserva. Em 1942 foi nomeado, por concurso, para exercer, em comissão o cargo de promotor público da Comarca de Foz do Iguaçu. Já em 1943 foi removido para a Comarca de Palmas e Prudentópolis. Neste mesmo ano, foi nomeado para exercer o cargo de Delegado de Polícia da Capital e Diretor do Departamento de Segurança e Chefe de Gabinete da mesma secretaria. Em 1948, foi designado para a $3^{a}$ curadoria da Capital. Promovido, por merecimento, para o cargo de promotor público da $4^{\mathrm{a}}$ entrância, assumiu a $1^{\mathrm{a}}$ Promotoria da Capital em janeiro de 1950. Em novembro do mesmo ano assumiu o cargo de $2^{\circ}$ Subprocurador Substituto. Em março de 1953 foi nomeado $4^{\circ}$ Subprocurador-Geral do Estado, sendo a partir de então designado para representar o Ministério Público de superior instância junto às Câmaras do Tribunal de Justiça. Em março de 1975, foi nomeado Procurador-geral de Justiça, cargo que exerceu até 1979. Nomeado em 17 de agosto de 1984 para exercer o cargo de desembargador do Tribunal de Justiça do Paraná, falecendo em 17 de junho de 1997. Uma de suas filhas, Jandira Sales de Albuquerque Maranhão, é casada com Anibal Khury Filho, filho do casal Anibal Khury (1924 1999) e Niva Sabóia Khury. São filhos do casal acima referido: Aníbal Khury Neto, falecido; Alexandre Maranhão Khury; Daniel Maranhão Khury e Rodrigo Maranhão Khury. 
Voltando à Raymundo e Cecília do Rego Almeida, o casal teve sete filhos, mas três morreram. São eles Felix do Rego Almeida, Carlos do Rego Almeida, Cecílio do Rego Almeida e Henrique do Rego Almeida.

Felix do Rego Almeida nasceu em Belém do Pará em 19/02/1928 e morreu em Curitiba em 27/12/1991. Foi sócio de Cecílio e um famoso médico, realizando mais de 40.000 operações na Santa Casa de Misericórdia. Félix casou com Nely Almeida, nascida em Bom Retiro (SC) e que veio a Curitiba para estudar na Universidade Federal do Paraná, onde se formou em História e Geografia, em 1957. Ela morava na Rua Marechal Deodoro junto com os pais e três irmãs, na mesma rua morava a família Rego Almeida. Quando Félix de apaixonou por Nely ele era noivo, porém desmanchou o noivado para casar com ela. Tiveram três filhos: Maria Cristina, engenheira; Elizabeth, médica; e Renato, também médico. Nely, acompanhando Félix, iniciou um trabalho social na Santa Casa de Misericórdia, liderando grupos de voluntários, inclusive na reconstrução do hospital depois de um incêndio. Foi um trabalho tão profícuo que um dia a convidaram para ser candidata a vereadora. Nely já havia trabalhado com Moysés Lupion, como secretária do PSD. Em 1988, foi a quinta mais votada entre 956 candidatos. Assumiu como vereadora em 1989, 1993, 1997, 2001 e 2005. Em 2011, para o sexto mandato, tomou posse no lugar da eleita deputada estadual Mara Lima, também do PSDB. O casal teve três filhos. Elisabeth Almeida, médica, tinha escritório particular na Rua Visconde de Nacar e passou a cuidar da clínica que seu pai mantinha junto a Santa Casa de Misericórdia. Maria Cristina Valente de Almeida, engenheira da turma de 1983 da Universidade Federal do Paraná, doutora em computação na Universidade de Stanford, residiu na Califórnia como técnica-senior de informática da Prefeitura de Los Angeles. Renato, filho caçula, formou-se em medicina.

Carlos do Rego Almeida foi Diretor Proprietário da CR Almeida. Seu filho, Caco Almeida, nasceu em Curitiba em 04/02/1967. Casado com Ângela Russi. Foi candidato a vereador em 2008 pelo PSB com 4.968 votos, sendo eleito suplente. É coordenador-geral da COMEC - Coordenação da Região Metropolitana de Curitiba - em 2014 e 2015, onde já foi diretor de Transportes da Comec. 
Henrique do Rego Almeida nasceu 16 de novembro de 1936 em Curitiba. Formado em Economia pela Faculdade de Ciências Econômicas do Paraná. Em 1990 foi eleito senador pelo PFL do Amapá para um mandato de quatro anos a ser renovado em 1994. Foi membro do conselho de consultivo e administrativo da empresa de engenharia CR Almeida. Fundou o grupo Hafil, que atua no ramo de loteamentos e incorporação imobiliária. O diretor superintendente do grupo é atualmente seu filho, Henrique do Rego Almeida Filho.

Cecílio do Rego Almeida nasceu em 31/01/1930 em Óbidos, Pará e se transferiu para o Paraná aos 7 anos de idade, com os pais e irmãos. Começou a trabalhar aos 9 anos, vendendo sementes para lavradores, laranja e palmito. Aos 14 anos prestou concurso para os Correios, onde começou a trabalhar como estafeta. A partir de 1949, quando iniciou o curso de Engenharia, passou a dar aulas de Matemática durante o dia e a trabalhar nos Correios à noite. Inclusive foi nos Correios, como operador da máquina Baudot, de cinco teclas, que adquiriu o hábito que levou até o fim da vida, de dedilhar à mesa durante reuniões de trabalho e conversas com os amigos.

A biografia de Cecílio se confunde com a história da CR Almeida que nasceu após cinco anos de experiência de Cecilio do Rego Almeida na tradicional construtora Lysimaco da Costa \& Irmão, quando passou a empreender seu próprio negócio, criando a Engenharia e Construções CR Almeida Ltda., em sociedade com seu irmão Félix, que era médico. Os irmãos Carlos, com 16 anos, e depois Henrique, de 23 anos, também participaram deste momento de gênese, quando a construtora ainda dava seus passos iniciais. Nos primeiros anos da CR Almeida, o escritório da empresa situava-se oficialmente na Marechal Deodoro, 1168, endereço da residência da família Almeida - uma casa pequena com três quartos, onde moravam os pais de Cecilio, ele e os irmãos.

A CR Almeida nasceu construindo bueiros em beira de estradas e cresceu muito ao participar de obras públicas. Em 1958 os primeiros trabalhos da empresa foram obras "pequenas", como construções de bueiros em rodovias, obras subempreitadas pela Lysimaco, por exemplo, a Curitiba-Paranaguá (BR-277), armazéns de café em Francisco Beltrão e Nova Esperança, e pistas de pouso de aviões no interior do Estado do Paraná, entre elas o Aeroporto de Cascavel. Em 1961 a empresa se muda para um novo escritório, localizado na Rua XV de Novembro, no centro de Curitiba e, apenas três anos após sua criação, passa a realizar contratos diretamente com o 
Departamento de Estradas de Rodagem (DER-PR), e tornou-se responsável pela construção de trechos importantes da estrada entre Curitiba e Paranaguá e de outras estradas no interior. Em 1962 incorpora a construtora SEP, a Sociedade de Engenharia do Paraná, e adquire o treço de obras de 40 km na região serrana de Alto do Amparo para a construção da Rodovia do Café (atual BR-376) unindo Apucarana, Ponta Grossa e Curitiba. Em 1963 compra outra construtora, a Guimarães \& Pierre, e passa a ser responsável pela obra de pavimentação da atual rodovia BR-269, entre Santa Mariana e Bandeirantes, importante treco de ligação entre o norte do Paraná e São Paulo. Em 1965 a CR Almeida compra a construtora Lysimaco e passou a tocar a construção de rodovias em Santa Catarina e Rio de Janeiro, o que permitiu uma participação mais ativa em grandes licitações, inclusive federais. A cada fusão a CR Almeida acumula obras, contatos e referências políticas.

Em 1969 a CR Almeida incorpora outra construtora, a paranaense Aranha S/A, empresa fundada nos anos 1930, com mais de 30 construções em andamento em diferentes estados. Com esta aquisição, a CR Almeida incorporou a Fábrica de Explosivos Britanite S/A. Também em 1969 a CR Almeida inicia as obras da Estrada de Ferro Central do Paraná que interligaria Apucarana a Ponta Grossa, uma obra com 321,5 km de estrada, $10 \mathrm{~km}$ de túneis e 3,5 km de viadutos, numa região de topografia complexa.

A Aranha S/A tinha como sócio Antônio Braga, pai de Ney Braga ${ }^{5}$, ex-empregado de uma padaria na Lapa, cria uma empreiteira construtora de obras, a Aranha S.A, com outros sócios, visando participar de construção e obras. O convite foi do então governador Manuel Ribas. Nos anos 40 e 50 a Empreiteira Aranha S.A de seu pai, Sr. Antônio Braga, vai prosperar a ponto de participar da construção da estrada que liga Joinville (estado de Santa Catarina) a Curitiba. Em janeiro de 1959, o DER entregou a pista asfaltada da rodovia Curitiba-São José dos Pinhais, via Boqueirão, obra fundamental para este bairro populoso (servindo ainda a Vila Hauer), pois era a

\footnotetext{
5 Ney Braga (Lapa, 25 de julho de 1917 - 16 de outubro de 2000), militar, prefeito de Curitiba, deputado federal, senador, governador do estado do Paraná, ministro da Agricultura, ministro da Educação e Presidente da Itaipu Binacional. Ney casa-se aos 22 anos com Maria José Munhoz da Rocha, filha do ex-governador Caetano Munhoz da Rocha (1920-1928) e irmã de Bento Munhoz da Rocha Neto (governador do estado do Paraná entre 1951 a 1955). Maria José faleceu precocemente em 1944 e, em 1949, Ney retorna a Curitiba e casa, pela segunda vez, com Nice Camargo Riesemberg com quem viverá até seus últimos dias.
} 
única via até o centro. Ligação mais curta e moderna com o aeroporto Afonso Penna, a inauguração do trecho fez parte das festividades do terceiro aniversário da administração do governo Lupion. O governador Moyses Lupion, que tinha estreitos laços de amizade com o Antonio Braga ortogou à empreiteira Aranha S.A. um contrato - feito pelo próprio diretor geral do DER Lolô Cornelsen, sem licitação - para a realização dos $28 \mathrm{~km}$ restantes, englobando o trecho da serra até a divisa, concluído em 1960, ainda no governo Lupion.

O sócio de Antônio Braga era Manoel Aranha, gaúcho de nascimento, filho do Coronel Euclides de Sousa Aranha e de Luísa de Freitas Vale Aranha, teve dez irmãos. O mais famoso deles foi Osvaldo Aranha, que participou ativamente da Revolução de 1930 e, entre outras funções, foi Ministro da Justiça, das Relações Exteriores e da Fazenda e representante do Brasil na primeira Assembléia da ONU. Seguindo a carreira militar do pai, Manoel Aranha chegou ao posto de capitão do Exército, servindo no Rio de Janeiro, então capital federal. Em maio de 1938, depois de participar do atentado contra Getúlio comandado pelos Integralistas foi reformado por decreto do Ministro da Guerra, Eurico Dutra, e veio morar em Curitiba. Então se tornou sócio da Aranha e também foi presidente do Atlético por apenas três anos, mas é considerado por muitos um dos maiores dirigentes que já passaram pelo clube. Para se ter uma idéia, sob seu comando o rubronegro foi campeão paranaense duas vezes (43 e 45) e vice no outro ano (44).

Em 1971, Cecílio do Rego Almeida foi o pivô da cassação do governador do Paraná Haroldo Leon Peres, da Arena. O empresário enviou ao presidente Emílio Médici uma gravação de conversa com Peres, em que este pedia uma comissão para liberar verbas devidas à construtora CR Almeida. Em entrevista à Folha, publicada em 1993, o empreiteiro admitiu que se dispunha a pagar uma propina de $4 \%$, mas que o governador queria cerca de $30 \%$. Almeida também acusou o governo Collor e uma construtora rival de corrupção em licitações de obras públicas.

Cecílio voltaria à cena nacional em março de 1974, por conta de um drama pessoal: seu filho César Beltrão de Almeida, de 12 anos, foi sequestrado no dia 25 e libertado 35 horas depois, após o pagamento do resgate exigido de 15 milhões de cruzeiros, equivalente hoje a 1,650 milhão de reais. Em Curitiba corre a versão de que Cecílio teria castigado dois dos doze criminosos envolvidos no 
crime: o mentor do sequestro foi jogado de um helicóptero em alto-mar. E outro detido, que cumpria pena no Presídio de Ahu, foi brindado com injeções diárias de hormônio feminino.

Nos marcos do PND II, em 1974 iniciaram-se as obras de construção da Usina Hidrelétrica de São Simão, ainda hoje a maior usina da Cemig, localizada na fronteira entre os Estados de Minas Gerais e Goiás. No auge das obras, trabalharam ali mais de 6.000 funcionários. O reservatório da usina é de 703 quilômetros quadrados de área, a barragem tem 127 metros de altura e comprimento de 3,5 quilômetros, com capacidade de geração de $2.680 \mathrm{MW}$. O volume de água em seu lago pode chegar a 12, 5 bilhões de metros cúbicos. Esta obra foi considerada um marco brasileiro na engenharia de hidrelétricas, e para realizá-la, a CR Almeida formou consórcio com a empresa italiana Impregilo, umas das maiores construtoras do mundo. Também em 1974 a CR Almeida foi responsável pela implantação da BR-290, conhecida como Freeway, entre as cidades de Osório e Santo Antonio da Patrulha, no Rio Grande do Sul, com 36 quilômetros de extensão. Foi a primeira do Estado a receber pista dupla. Em 1975 a CR Almeida foi responsável pela construção da estrada Rio-Santos, no trecho de 34,7 quilômetros entre a divisa do Rio de Janeiro e São Paulo, com traçado que acompanha a Serra do Mar, com frequentes contatos da rodovia com o maciço rochoso dos contrafortes. Em 1976 a CR Almeida foi responsável pela construção de 17,8 quilômetros da Rodovia dos Bandeirantes, no trecho entre Vinhedo e Campinas, em São Paulo. Em 1977, em parceria internacional feita com a empresa alemã Preussag, a CR Almeida realizou a construção de um terminal petrolífero e de um oleoduto, de Angra dos Reis até Duque de Caxias, com 135 quilômetros, em obra contratada pela Petrobras.

Apesar da crise dos anos 1980, em 1981 a CR Almeida implanta a segunda pista da BR-277, interligando Curitiba a Paranaguá. Em 1982, construiu um trecho de 184 km da Estrada de Ferro Carajás, entre Santa Inês e Buriticupu, no Maranhão. Em 1988 construiu três túneis de desvio do Rio Iguaçu, cada um com 13,5 metros de diâmetro, totalizando 2,1 quilômetros de extensão, na Usina Hidrelétrica de Segredo, entre os municípios de Mangueirinha e Reserva do Iguaçu, no Paraná. A Usina possui potência de 1.260 MW. 
No governo Lerner, a CR Almeida ingressa no segmento de concessões. Em 14 de novembro de 1997 a Primav, empresa criada para essa nova área de negócio, firmou seu primeiro contrato com o Departamento de Estradas de Rodagem do Paraná para a concessão de importante trecho rodoviário incluído no Programa de Concessões Rodoviárias do Estado do Paraná: o trecho de ligação com o litoral da BR-277, a estrada Curitiba-Paranaguá - operacionalizada pela Ecovia Caminho do Mar, também criada para essa finalidade. Inicia-se a história do Grupo EcoRodovias, uma das maiores empresas de infraestrutura e logística integrada do Brasil, responsável por administrar quinze plataformas logísticas, cinco concessões rodoviárias e uma área portuária. Depois o Grupo se envolveu em licitações relacionadas à oferta da banda $\mathrm{B}$ de telefonia celular no interior paulista.

Nos anos 90 o empreiteiro foi acusado de grilagem de uma fazenda com 7 milhões de hectares de pura selva no sul do Pará, uma área do tamanho da Bélgica e da Holanda juntas. Além do tamanho, suas terras, localizadas no coração da Amazônia, são riquíssimas, com reservas de diamante, ouro e cassiterita, ainda não quantificadas. Com 60 milhões de metros cúbicos de madeira, o empreiteiro também reúne no seu território uma das últimas grandes reservas de mogno do planeta, avaliada numa fortuna bilionária. Estas terras são cinco vezes maiores que as do empresário americano Daniel Ludwig, que nos anos 70 chamou a atenção do Brasil ao tentar implantar, no meio da floresta, o célebre Projeto Jari, para produzir celulose, arroz e carne bovina em quantidades exponenciais. As terras de Cecílio são ainda dez vezes mais extensas que as da Fordlândia, apelido do megaprojeto criado nos anos 20 pelo pioneiro da indústria automobilística, o americano Henry Ford, que queria transformar o Pará num centro mundial de produção de borracha.

Em 1997 ganhou uma benesse da Justiça numa decisão do Supremo Tribunal Federal em que o empreiteiro recebeu um precatório de cerca de $\mathrm{R} \$ 1,8$ bilhão por ter construído para o Estado a ferrovia Paraná Central, em 1968, que liga Apucarana a Ponta Grossa, uma obra concluída então há mais de 20 anos. A receita do Paraná em 1997 foi de R \$ 4,8 bilhões.

Em 2000 a CR Almeida conclui as obras de implantação do anel viário da cidade de São Paulo, a Estrada do Pêssego e Córrego do Jacu, com 33,3 quilômetros de extensão, uma das maiores avenidas urbanas do mundo. Ao longo dos anos 2000, outros dois contratos para extensão do 
mesmo anel viário foram firmados e cumpridos. Em 2002 concluiu a construção do Viaduto Estaiado e da Ponte Laranjeiras, na Baixada Santista, em São Paulo. O primeiro, localizado na rodovia Interligação Baixada (SP-059), foi o primeiro viaduto Estaiado construído pela empresa. Possui 170 m de extensão (dois vãos de 85 metros) e um pilar central com duas torres de altura de 45 metros. Já a ponte sobre o Rio Laranjeiras possui extensão total de 527 metros com doze vãos de 44 metros. Em 2002 também concluiu as obras da pista descendente da Rodovia dos Imigrantes, que liga a cidade de São Paulo a Santos e região. Essa construção é considerada um marco do retorno das grandes obras de infraestrutura no País, após praticamente duas décadas de estagnação. Os serviços compreenderam a construção dos 20 quilômetros de extensão da nova pista, 4.275 metros de viadutos e 8.230 metros de túneis. Foram empregadas, de forma pioneira, novas tecnologias na perfuração dos túneis e na construção de viadutos. A Ecovias dos Imigrantes, concessionária que administra o Sistema Anchieta Imigrantes, foi a responsável pela contratação da obra. A Britanite também participou desta empreitada, fornecendo os explosivos utilizados na construção. Em um momento especial para o Grupo CR Almeida, suas três áreas estratégicas trabalharam juntas numa mesma obra de grandes proporções.

Em 2003, o próprio Grupo transformou-se em uma holding. Em 2004 iniciou as obras do Novo Centro Maringá, realizando o rebaixamento da linha férrea que cruza o centro da cidade de Maringá, Paraná. Em 2006 deu início às obras do Rodoanel Mário Covas, em São Paulo. A Construtora ficou responsável pelo lote três do Rodoanel, que possui 5.758 metros de extensão no eixo principal, cruzando a Rodovia dos Imigrantes e passando pelos municípios de São Bernardo do Campo e São Paulo. O projeto do lote três contemplou ainda vinte e uma obras de arte especiais, entre elas dezoito viadutos e três pontes, bem como 22 quilômetros de malha viária, correspondentes às alças de acesso ao Rodoanel e à Rodovia dos Imigrantes. Também em 2006 a CR Almeida iniciou as obras de duplicação, reforço, alargamento, recuperação e restauração da pista existente e de pontes na rodovia BR-101/PB, lote 3, trecho Natal - Palmares/PB, com 40,4 quilômetros.

Em 22 de março de 2008 morre Cecílio, deixando um patrimônio estimado em R \$ 9,4 bilhões e cerca de 30 empresas nas áreas de construção, concessão de rodovias, logísticas de 
transporte e química. O novo presidente do Conselho de Administração passou a ser Marco Antônio Cassou, casado com Denise, a única mulher entre os seis filhos de Cecílio.

Cecílio foi casado duas vezes. A primeira esposa foi Rosa Maria Beltrão, da tradicional família Beltrão, filha de Cornélia de Castro Beltrão e Dr. Alexandre Gutierrez Beltrão.

A origem da família Beltrão no Paraná começou com a vinda do Desembargador Francisco da Cunha Machado Beltrão, natural de Pernambuco de 17 de outubro de 1845. Era filho do industrial e bacharel Pedro Bezerra de Araújo Beltrão e Alexandrina da Cunha Machado Pedrosa Beltrão, de tradicionais famílias da aristocracia rural pernambucana. Alguns apontam que os ascendentes da família Beltrão eram portugueses do bispado de Porto. Em 1872, Francisco Beltrão casou em Paranaguá com Rosa Branca Correa Gutierrez, nascida em Montevidéu em 1 de janeiro de 1858, falecida em novembro de 1920.

Dois municípios no interior do Paraná levam os nomes da família Beltrão (Engenheiro Beltrão, em homenagem a Alexandre Gutierrez Beltrão, e Francisco Beltrão). A família Beltrão multiplicou-se por meio de casamentos com descendentes dos Correia e Guimarães, as principais famílias na exportação de erva-mate. Desde o século XVIII, a parentela de Manoel Antonio Guimarães, o Visconde de Nácar, importante ervateiro e proprietário escravista, sempre reproduziu as relações entre grandes empreendimentos econômicos e posições no aparelho de Estado e na magistratura. O Barão do Serro Azul, Ildefonso Pereira Correia, o maior ervateiro do Paraná em meados do século XIX, era seu descendente (OLIVEIRA, 2007).

Rosa Maria Beltrão era neta do Major Vicente Ferreira de Castro, o primeiro republicano histórico da Villa de Palmeira, município paranaense. Exerceu no Governo Provisório o cargo de Vice Presidente da Câmara Municipal. Foi ao lado do Padre João Batista de Oliveira, um dos chefes da revolução de 1893-94, quando assumiu o comando do Batalhão "Jesuino Marcondes" e com ele marchou para o Rio Grande do Sul com a Brigada do General Thimotheo Paim. Posteriormente passou a fazer parte da Brigada do General Apparicio Saraiva. Tomou parte no Grande combate do Pinheiro Marcado - onde foi ferido por bala de manlicher. Com o falecimento do General Gumercindo Saraiva, continuou com o General Apparicio até emigrarem para a Argentina pela 
picada da Collonia do Alto Uruguay. Com o armisticio, concedido pelo Presidente Prudente de Moraes, regressou ao Paraná, onde continuou obedecendo a orientação política do Chefe Dr. Generoso Marques dos Santos. Pelo Presidente Prudente de Moraes foi nomeado Major da Guarda Nacional. Muito relacionado em todo Paraná. Em 1896 passou a residir em Ponta Grossa, tendo ali aos poucos conquistado a chefia política até 1922. Exerceu o Cargo de primeiro Suplente de Juiz Federal do Paraná em 1921. Foi chefe de numerosa família.

A mãe de Rosa era Cornélia de Castro Beltrão, a primeira mulher do Estado do Paraná a obter carta de habilitação para dirigir veículo. Cornélia era casada com Dr. Alexandre Guttierres Beltrão, engenheiro civil, filho do Desembargador, Francisco Machado da Cunha Beltrão e Rosa Guttierres Beltrão. Seu irmão, o médico Lauro Castro Beltrão foi professor e um dos fundadores da Universidade Estadual de Londrina. A prima Dalila de Castro Lacerda foi casada com o Engenheiro Civil Dr. Flavio Suplicy de Lacerda, filho do Cel. Manuel Jose de Lacerda e Alice Suplicy de Lacerda.

Cargos centrais no governo estadual, na Prefeitura de Curitiba e no poder judiciário sempre estiveram associados às ambições e os interesses desses grupos, ligados a grandes investimentos imobiliários e a grandes empresas. Mais recentemente Alexandre Fontana Beltrão, por exemplo, ocupou diversos cargos no estado Paraná. Durante 26 anos, esteve na International Coffe Organization, foi Presidente do Instituto de Tecnologia do Paraná (TECPAR) e Secretário de Estado de Assuntos Estratégicos e de Ciência, Tecnologia e Ensino Superior, respondendo a vários processos no Tribunal de Contas do Paraná. Em um deles, foi absolvido pelo Presidente do TC, Henrique Naigeboren, indicado para o Tribunal por Jaime Lerner, seu cunhado.

Rosa Beltrão e Cecílio Almeida se separaram na década de 1990. Depois do divórcio Rosa casou com Karlos Rischbieter. Nascido em Blumenau, em Santa Catarina, em 1927, Rischbieter veio a Curitiba aos 18 anos para cursar engenharia na Universidade Federal do Paraná. Foi presidente da Caixa Econômica Federal, do Banco do Brasil e do extinto Banco do Desenvolvimento do Paraná (Badep) e ministro da Fazenda entre 1979 e 1980, no governo João Figueiredo. Sua primeira esposa foi a engenheira Francisca Maria Garfunkel Rischbieter, conhecida como "Franchette", uma das pioneiras no trabalho de planejamento urbano da capital 
paranaense. Formada pela turma 1950 da Universidade Federal do Paraná, começou a trabalhar na divisão de pavimentação da cidade e em 1963 foi nomeada diretora do Departamento de Urbanismo. Franchette acompanhou o planejamento urbano desde 1965, antes mesmo da criação da Assessoria de Pesquisa e Planejamento Urbano de Curitiba, transformada depois em IPPUC. Francisca faleceu em 27 de agosto de 1989, aos 60 anos, de câncer, em Curitiba. Ironicamente, Franchette tinha uma frase na ponta da língua para receber o empreiteiro Cecílio do Rego Almeida no seu gabinete da Prefeitura de Curitiba pelos idos da década de 1970: "Qual foi a irregularidade que você veio me propor hoje?". O casal Karlos e Franchette teve dois filhos. Monica Rischbieter é produtora, roteirista e esteve no comando da secretária estadual da Cultura e do Teatro Guaíra durante o governo de Jaime Lerner. No governo Richa é novamente diretora do Teatro Guaíra. Luca Rischbieter é consultor pedagógico da Positivo Informática Tecnologia Educacional desde 1994.

A segunda esposa de Cecílio foi Angela Maria Brandão de Almeida, jornalista que se casou recentemente com o cirurgião plástico carioca José Horácio Aboudib, então presidente da Sociedade Brasileira de Cirurgia Plástica. Faz parte do Iate Clube de Santa Catarina.

Cecílio do Rego Almeida e Rosa Beltrão tiveram seis filhos. São eles Ricardo, Denise, Roberto, César, Guilherme e Marcelo.

Ricardo Beltrão de Almeida é engenheiro civil. Casado com Mônica Rigotto (mocellin?), arquiteta. O filho é Bernardo Mocellin de Almeida.

Denise Beltrão de Almeida é a única filha de Cecílio e Rosa. Engenheira agrônoma, casou com Marco Antônio Cassou. Nascido em 28 de maio de 1957. Formação acadêmica em Engenharia Civil pela Universidade Federal do Paraná (UFPR), com mestrado em Administração pela Stanford University (Califórnia, EUA). Foi gerente de Produção da Alusan Indústrias Químicas; gerente de Produção da EBEC Engenharia Brasileira de Construções; engenheiro civil, co-responsável técnico, diretor comercial e presidente da CR Almeida S.A. Engenharia e Construções; diretor administrativo e financeiro e presidente da Britanite Indústrias Químicas; diretor administrativo e financeiro da Rochesa Tintas e Vernizes e presidente do Sindicato das Indústrias Químicas do Estado do Paraná. É presidente do conselho de administração e presidente da CR Almeida S.A. Engenharia e Construções. 
O casal tem três filhas. Fernanda, graduada em Arquitetura e Urbanismo pela Pontifícia Universidade Católica do Paraná (2009), possui estudos complementares na Espanha. Em 2013 fundou o escritório Fernanda Cassou Arquitetura que atua em projetos residenciais, comerciais e eventos sempre buscando mostrar contemporaneidade e sua identidade. Fernanda casou com André Nacli, filho da socióloga Cristina Nacli e do engenheiro Jorge Nacli, unindo duas grandes riquezas do Paraná. A irmã, Carolina casou com Luis Felipe Meneghetti, de tradicional família londrinense. E Mariana Cassou casou com Raul Frare.

Roberto Beltrão de Almeida, o Beto Almeida, era membro do conselho de consultivo e administrativo da empresa de engenharia CR Almeida e era parceiro do ex-prefeito de Curitiba, Beto Richa, nas corridas de kart. Casado com Amanda Veiga de Almeida. Beto Almeida morreu vítima de uma infecção generalizada causada por uma bactéria no Hospital Santa Cruz.

César Beltrão de Almeida nasceu em 03 de outubro de 1962. Formação acadêmica em Engenharia Civil pela Universidade Federal do Paraná (UFPR), com pós-graduação no MBA Executivo da Fundação Getulio Vargas em Team Management. Foi engenheiro civil, Diretor de Apoio a Presidência, Diretor Financeiro e Diretor Superintendente Administrativo Financeiro da CR Almeida S.A. Engenharia e Construções. Atualmente é Sócio-Fundador da Prospecta Fomento Mercantil S.A e Procrédito Consultoria e Assessoria Financeira Ltda e Sócio-Gerente do Grupo Pater (CBB Asfaltos, Tb Transportes e Bosca Asfaltos). É membro do Conselho de Administração do Grupo CR Almeida e desde 2009 é membro do Conselho de Administração da EcoRodovias.

Guilherme Beltrão de Almeida, casado, assessor jurídico da CR Almeida e sócio da Beltrão de Almeida Advogados Associados.

Marcelo Beltrão Almeida nasceu em Curitiba (PR), em 1966. Marcelo se formou em Engenharia Civil, pela PUC-PR, mas preferiu se dedicar à vida pública. Por duas vezes, foi eleito vereador de Curitiba, em 1992 e 2000. Também já atuou como diretor geral do Departamento de Trânsito do Paraná (Detran-PR) e secretário estadual de Obras Públicas do Paraná, durante a gestão do governador Roberto Requião. Assumiu o cargo de deputado federal pelo PMDB paranaense em 2008, como suplente do ministro da Agricultura Reinhold Stephanes. Casado e pai de quatro filhos, Marcelo Beltrão Almeida declarou um patrimônio de R\$ 83 milhões à Justiça Eleitoral em 2006. Na 
candidatura ao Senado em 2014, Marcelo declarou o maior patrimônio à Justiça Eleitoral dentre os 178 postulantes ao cargo no país com $\mathrm{R} \$ 740$ milhões.

\section{BRIEF GENEALOGICAL STUDY CECILIO REGO ALMEIDA}

\section{ABSTRACT}

The purpose of this article is to describe and analyze the social and political profile of Cecilio Family members do Rego Almeida, founder and owner of CR Almeida, one of the largest in the history of Paraná.

Key-words: Genealogy. Cecilio do Rego Almeida. Family. Trajectory. 